\title{
Cytogenetic and AFLP Fingerprints for Five Species of Thai Macaques
}

\author{
Tawatchai Tanee ${ }^{1}$, Arunrat Chaveerach ${ }^{2, *}$ Nison Sattayasai $^{1}$, \\ Alongkoad Tanomtong ${ }^{2}$, Scott A. Suarez ${ }^{3}$ and Suporn Nuchadomrong ${ }^{1}$ \\ ${ }^{1}$ Department of Biochemistry, Faculty of Science, Khon Kaen University, Khon Kaen, \\ Thailand \\ ${ }^{2}$ Department of Biology, Faculty of Science, Khon Kaen University, Khon Kaen, Thailand \\ ${ }^{3}$ Department of Anthropology, Miami University, Ohio, USA
}

Received July 6, 2006; accepted July 22, 2006

\begin{abstract}
Summary Genetic studies of 5 species of macaques using G-banding patterns were investigated. Blood samples of them were examined using lymphocyte culture technique. The results indicate that they have identical data including the number of diploid chromosome is 42 ; the types of autosomes are metacentrics and submetacentrics viz. 6 large metacentrics, 4 medium metacentrics and 8 small metacentrics, and 8 large submetacentrics, 12 medium submetacentrics and 2 small submetacentrics; the short arm of chromosome pair 13 is a satellite chromosome. A few difference is X and $\mathrm{Y}$ chromosome. The $\mathrm{X}$ and $\mathrm{Y}$ chromosomes are medium submetacentrics and medium metacentrics, and small submetacentric, medium submetacentric and small telocentrics, respectively. The cytogenetic studies show that all 5 species Thai macaques have a common evolutionary relationship. For studying in depths, molecular markers were assessed using the Amplified Fragment Length Polymorphism (AFLP) method. The AFLP fingerprints from 7 primer combinations were compared. A total of 1754 bands, with 890 (50.71\%) polymorphic bands, were generated. Seven monomorphic bands $(0.78 \%)$ were found in all individuals of macaques. The average genetic distance (D) between species based on AFLP analysis shows 0.269 to 0.380 . The developing of specific cytogenetic and AFLP fingerprints of a species is possible further benefit for humanity.
\end{abstract}

Key words AFLP fingerprints, Chromosome, Cytogenetic, G-banding, Macaca.

The macaques, genus Macaca, represent one of the most successful populations within the order Primates. Their geographical distribution ranks second in size among extant primates, with humans taking first place (Deinard and Smith 2001). Although the number of macaque species depends on the classification scheme used, most authors follow the classification determined by Fooden (1976) or Delson (1980), which recognizes 19 extant macaque species. In Thailand, there are 5 species, Macaca arctoides, M. assamensis, M. fascicularis, M. mulatta, and M. nemestrina, which represent all four defined groups, silenus-sylvanus (M. nemestrina), fascicularis (M. fascicularis and M. mulatta), arctoides (M. arctoides) and sinica (M. assamensis), based on the morphological classification scheme by Fooden (1976). Delson (1980) proposed a slightly different classification, which classifies $M$. sylvanus into its own group and includes $M$. arctoides in the sinica group.

The relationship between monkeys and humans has occurred for a long time as monkeys, macaques, gibbons and apes share a common ancestor with humans, we share many basic features of genetics, development, physiology, and metabolism (Jones et al. 2004). Therefore, many basic and applied scientific investigations of macaques have aimed to cover aspects of their physiology that may be beneficially utilized by humans. Rhesus monkeys are in high demand for biomedical research of human health issues, ranging from diseases and disorders to potential therapies and pre-

*Corresponding author, e-mail: raccha@kku.ac.th 
ventive strategies. International initiatives that address the medical threats of bioterrorism and aim to reduce the prevalence of AIDS depend on scientific access to Rhesus monkeys (The Research Resources Information Center 2002). Cytogenetic and molecular markers of a species should be developed for further human applications, such as research on vaccines for AIDS, neurobiology and mental illness, immunology, aging, diabetes, pharmacogenetics and many others.

The Amplified Fragment Length Polymorphism (AFLP) technique is one DNA fingerprinting procedure which uses the Polymerase Chain Reaction (PCR) to amplify a limited set of DNA fragments from a specific DNA sample. Since AFLP analysis does not require prior genetic information of the taxa studied, it should be of value in phylogenetic analysis of a wide variety of organisms. Furthermore, AFLP phenotypes were highly reproducible and, thus, reliable (Vos et al. 1995). The AFLP markers have been widely applied in plant studies and more recently to study genetic variation, phylogenic analysis (John et al. 2004, Moreno et al. 2002, Pelser et al. 2003, Riberon et al. 2004, Ude et al. 2003, Wang et al. 2003), and gene mapping among animals such as, rats (Otsen et al. 1996), cattle (Ajmone-Marsan et al. 1997) and poultry (Knorr et al. 1999).

The present study aims to establish standard karyotypes for cytogenetic markers and DNA fingerprints for molecular markers of a species of the 5 Macaca species.

Material and methods

\section{Sample collection}

A total of 12 blood samples of macaques representing 5 macaque species, Macaca arctoides, M. assamensis, M. fascicularis, M. mulatta, and M. nemestrina were collected from northeastern and southern Thailand (Table 1). The samples of each individual were divided into 2 groups, the first for cytogenetic analysis and the second for molecular analysis.

\section{Cytogenetic analysis}

Blood samples were subjected to cytogenetic studies by lymphocyte culture of whole blood. The cultured cells were examined by the colchicines-hypotonic fixation-air drying technique followed by G-banding with Giemsa (Campiranon 1999). Chromosomal checks were performed with 20 cells of each individual by light microscopy.

\section{Molecular analysis}

DNA isolation

Genomic DNA was extracted from blood samples following Sambrook and Russel (2001). The quality and quantity of extracted DNA was assessed by $0.8 \%$ agarose gel electrophoresis and spectrophotometry.

\section{AFLP reaction}

The procedures of AFLP method (Vos et al. 1995) were performed according to the protocol

Table 1. The sources of specimens used in this study

\begin{tabular}{|c|c|c|c|c|c|}
\hline Species & Individuals & $\begin{array}{l}\text { Sources } \\
\text { (regions in Thailand) }\end{array}$ & Species & Individuals & $\begin{array}{c}\text { Sources } \\
\text { (regions in Thailand) }\end{array}$ \\
\hline Macaca arctoides & $\begin{array}{l}\text { arctoides } 1 \\
\text { arctoides } 2\end{array}$ & $\begin{array}{l}\text { Northeast } \\
\text { South }\end{array}$ & M. fascicularis & $\begin{array}{l}\text { fascicularis } 4 \\
\text { fascicularis } 5\end{array}$ & $\begin{array}{l}\text { South } \\
\text { South }\end{array}$ \\
\hline M. assamensis & assamensis 1 & Northeast & M. mulatta & mulatta 1 & Northeast \\
\hline \multirow{3}{*}{ M. fascicularis } & fascicularis 1 & Northeast & & mulatta 2 & South \\
\hline & fascicularis 2 & Northeast & M. nemestrina & nemestrina 1 & Northeast \\
\hline & fascicularis 3 & South & & nemestrina 2 & South \\
\hline
\end{tabular}


of the Kit (AFLP ${ }^{\mathrm{R}}$ Analysis System I, Invitrogen, USA). After adaptor ligation and preselective amplification, selective amplification was conducted with seven primer combinations: E-ACC/MCAG, E-AAC/M-CAT, E-AAC/M-CAG, E-AAG/M-CAT, E-AAG/M-CTT, E-AGG/M-CTT and EAGC/M-CAT. The PCR products amplified with different primer combinations were loaded onto $6.0 \%$ denaturing polyacrylamide gels, electrophoresed for $3 \mathrm{~h}$, and detected by Silver Quest ${ }^{\mathrm{TM}}$ Sil- $^{-}$ ver Staining Kit (Invitrogen, USA).

\section{Data analysis}

Data points are the absence (0) and presence (1) of each band across all samples with the same primer pairs. These $0 / 1$ data were used to analysis the genetic distances with Fingerprinting II program (Bio-Rad, USA).

\section{Results}

Results from lymphocyte culture of whole blood and G-banding staining of the 5 macaque species namely Macaca arctoides, $M$. assamensis, M. fascicularis, M. mulatta, and M. nemestrina indicate that all species show a diploid chromosome ( $2 n)$ number of 42 consisting of 40 autosomes and 2 sex chromosomes; the types of autosomes are only metacentrics and submetacentrics viz. 6 large metacentrics, 4 medium metacentrics and 8 small metacentrics, and 8 large submetacentrics, 12 medium submetacentrics and 2 small submetacentrics; the short arm of chromosome pair 13 is a satellite chromosome. A few difference is $\mathrm{X}$ and $\mathrm{Y}$ chromosome. The $\mathrm{X}$ chromosome is medium submetacentrics and medium metacentrics. The $\mathrm{Y}$ chromosome is small submetacentric, medium submetacentric and small telocentrics (Table 2 and Figs. 1-3). The cytogenetic studies show that all 5 species of Thai macaques have a common evolutionary relationship.

Table 2. Cytogenetics of five macaque species by means of lymphocyte culture of whole blood and Gbanding staining

\begin{tabular}{|c|c|c|c|c|c|c|c|c|c|}
\hline \multirow{3}{*}{ Sample studied } & \multirow{3}{*}{$\begin{array}{l}\text { Diploidy } \\
\text { (2n) }\end{array}$} & \multicolumn{6}{|c|}{ Autosomes types and numbers } & \multirow{2}{*}{\multicolumn{2}{|c|}{$\begin{array}{c}\text { Sex chromosomes } \\
\text { types }\end{array}$}} \\
\hline & & \multicolumn{3}{|c|}{$\mathrm{m}$} & \multicolumn{3}{|c|}{$\mathrm{sm}$} & & \\
\hline & & $\mathrm{L}$ & M & $\mathrm{S}$ & $\mathrm{L}$ & M & $\mathrm{S}$ & $\mathrm{X}$ & $\mathrm{Y}$ \\
\hline M. arctoides & 42 & 6 & 4 & 8 & 8 & 12 & 2 & $\operatorname{sm}(\mathrm{M})$ & $\operatorname{sm}(\mathrm{S})$ \\
\hline M. assamensis & 42 & 6 & 4 & 8 & 8 & 12 & 2 & $\operatorname{sm}(\mathrm{M})$ & $\mathrm{t}(\mathrm{S})$ \\
\hline M. fascicularis & 42 & 6 & 4 & 8 & 8 & 12 & 2 & $\mathrm{~m}(\mathrm{M})$ & $\mathrm{t}(\mathrm{S})$ \\
\hline M. mulatta & 42 & 6 & 4 & 8 & 8 & 12 & 2 & $\mathrm{~m}(\mathrm{M})$ & $\mathrm{m}(\mathrm{S})$ \\
\hline M. nemestrina & 42 & 6 & 4 & 8 & 8 & 12 & 2 & $\operatorname{sm}(\mathrm{M})$ & $t(S)$ \\
\hline
\end{tabular}

$\mathrm{m}=$ metacentrics, $\mathrm{sm}=$ submetacentrics, $\mathrm{t}=$ telocentrics, $\mathrm{M}=$ medium chromosome, $\mathrm{S}=$ small chromosome.

Table 3. The average genetic distance based on the AFLP analysis of five macaque species from Thailand and Homo sapiens

\begin{tabular}{|c|c|c|c|c|c|c|}
\hline Samples studied & M. fascicularis & M. mulatta & M. nemestrina & M. assamensis & M. arctoides & H. sapiens \\
\hline M. fascicularis & 0.000 & & & & & \\
\hline M. mulatta & 0.288 & 0.000 & & & & \\
\hline M. nemestrina & 0.294 & 0.269 & 0.000 & & & \\
\hline M. assamensis & 0.375 & 0.302 & 0.375 & 0.000 & & \\
\hline M. arctoides & 0.356 & 0.326 & 0.367 & 0.380 & 0.000 & \\
\hline H. sapiens & 0.443 & 0.419 & 0.470 & 0.387 & 0.443 & 0.000 \\
\hline
\end{tabular}



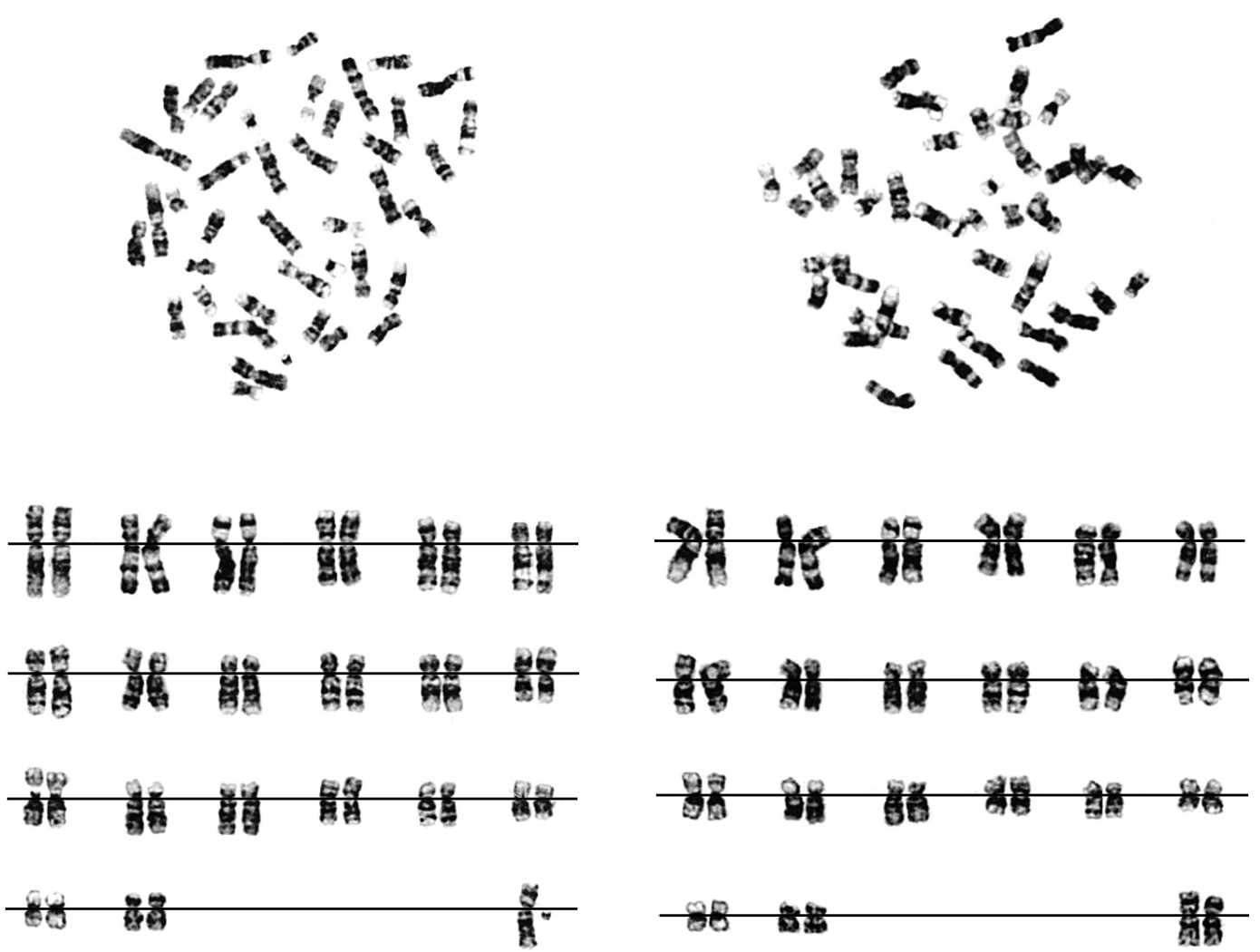

Fig. 1. G-banding patterns of metaphase chromosomes (above) and karyotypes (below) of male Longtailed macaque (Macaca fascicularis), $2 n=42$.

Fig. 2. G-banding patterns of metaphase chromosomes (above) and karyotypes (below) of female Longtailed macaque (Macaca fascicularis), $2 n=42$.

AFLP fragments were established for 12 individuals of 5 macaque species. Seven primer combinations yielded a total of 1754 scorable bands of which 890 bands $(50.71 \%)$ were polymorphic. Seven monomorphic bands $(0.78 \%)$ are found in all macaque individuals (Fig. 4). Averages of inter-specific genetic distance (D) values among all studied species are 0.269 to 0.380 (Table 3 ).

\section{Discussion}

The results of cytogenetic studies have no diversity in the autosome viz. the karyotypes, the types and numbers of autosomes and the 13th satellite chromosome pair, except for a few differences in the $\mathrm{X}$ and $\mathrm{Y}$ chromosomes. The results support Brown et al. (1986), reflecting the close evolutionary relationship among species in the genus Macaca. According to the close evolutionary relationship, the D values are low. However, the AFLP fingerprint of each species can be more specific.

Currently, the loss of specific, genetic and ecological diversities caused by human disturbance is a serious problem in Thailand. Forest destruction negatively affects wild animals such as macaques. It reduces habitats for wild animals and causes population fragmentation. These isolated populations rapidly lose genetic heterogeneity and become vulnerable to environmental change and risk extinction. One more factor leading to genetic loss is the ability of interspecific intercross causing from close evolutionary relationship (Brown et al. 1986). The genetics of a species might be lost. 


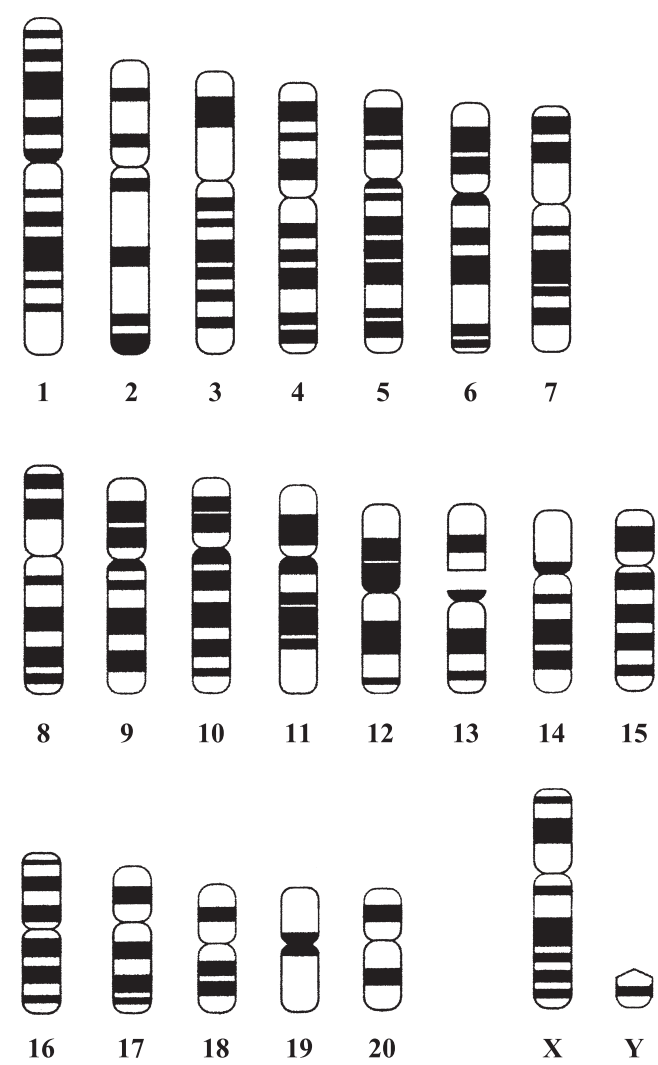

Fig. 3. Idiogram of metaphase chromosomes of the male Long-tailed macaque (Macaca fascicularis) showing the satellite chromosome pair 13.
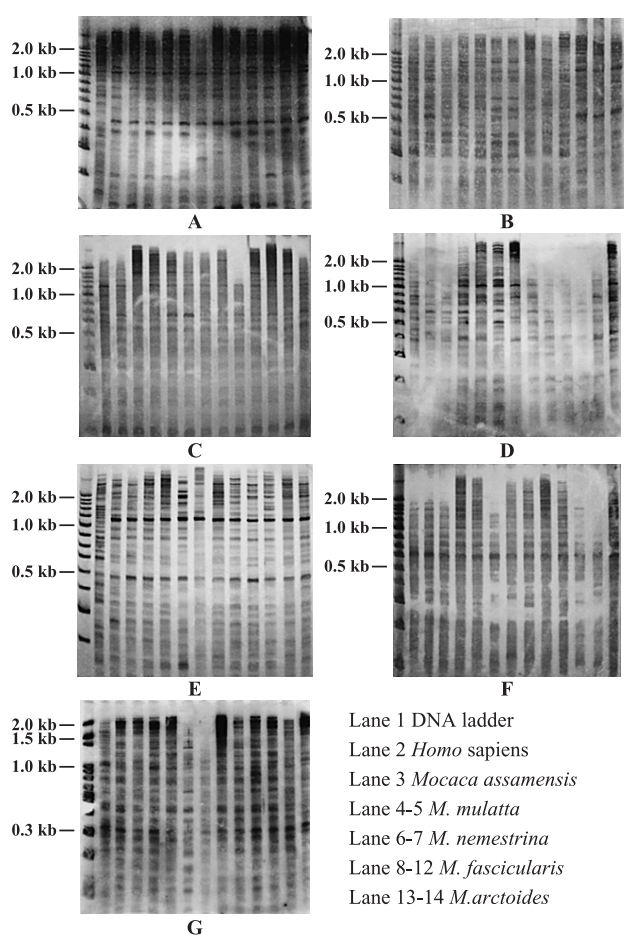

Lane 1 DNA ladder

Lane 2 Homo sapiens

Lane 3 Mocaca assamensis

Lane 4-5 M. mulatta

Lane 6-7 M. nemestrina

Lane 8-12 M. fascicularis

Lane 13-14 M.arctoides

Fig. 4. AFLP fingerprints of five macaque species with the seven primer combinations viz. EcoRIAAC/MseI-CAG (A), EcoRI-AAC/MseI-CAT (B), EcoRI-AAG/MseI-CAT (C), EcoRI$\mathrm{AAG} / M s e \mathrm{I}-\mathrm{CTT}$ (D), EcoRI-ACC/MseI-CAG (E), EcoRI-AGC/MseI-CAT (F), EcoRIAGG/MseI-CTT (G).

Genetic changes can be divided into 2 groups, those which result in changes in proteins, such as enzymes, and those which affect regulatory genes (Carson 1975). Comprising the above mention, the macaques are great useful for humanity, a private fingerprint is selected to indicate a species apart from the sex chromosome. The AFLP technique is suitable for producing due to amplify a limited set of DNA fragments from a specific DNA samples with reproducible band patterns. DNA pattern variation in a species may be occurred with various area collected sample following genetic variation upon geographically distributed areas like $M$. fascicularis originating from the Northeast and South Thailand (Fig. 4). Whenever critical crisis appears, the 7 AFLP primer combinations can be used to produce bands for all sample studies and polymorphisms, which was sufficient to determine genetic differentiation in 5 macaque species.

\section{Acknowledgement}

This work was supported in part by Khon Kaen University's Graduate Research Fund, Academic Year 2004.

\section{References}

Ajmone-Marsan, P., Valentini, A., Cassandro, M., Vecchiotti-Antaldi, G., Bertoni, G. and Kuiper, M. 1997. AFLP markers 
for DNA fingerprinting in cattle. Animal Genetics 28: 418-426.

Brown, C. J., Dunbar, V. G. and Shafer, D. A. 1986. A comparison of the karyotypes of 6 species of the genus Macaca and a species of the genus Cerocebus. Folia Primatology 46: 164-172.

Campiranon, A. 1999. Human Genetics. Department of Genetics, Faculty of Science, Kasetsart University Press, Bangkok.

Carson, H. L. 1975. The genetics of speciation at the diploid level. American Naturalist 109: 83-92.

Deinard, A. and Smith, D. G. 2001. Phylogenetic relationships among the macaques: evidence from the molecular locus NRAMP1. Journal of Human Evolution 41: 45-59.

Delson, E. 1980. Fossil Macaques, Phylogenetic Relationships and Scenario of Development. In: Lindburg, D. (ed.). The Macaques: Studies in Ecology, Behavior and Evolution. Van Nostrand Reinhold, New York. pp. 10-30.

Fooden, J. 1976. Provisional classification and key to living species of macaques (primates: Macaca). Folia Primatologica 25: $225-236$.

John, U., Groben, R., Beszteri, B. and Medlin, L. 2004. Utility of amplified fragment length polymorphisms (AFLP) to analyze genetic structures within the Alexandrium tamarense species complex. Protist 155: 169-179.

Knorr, C., Cheng, H. H. and Dodgson, J. B. 1999. Application of AFLP markers to genome mapping in poultry. Animal Genetics 30: 28-35.

Moreno, Y., Ferrus, M. A., Vanoostende, A., Hernandez, J., Montes, R. M. and Hernandez, J. 2002. Comparison of 23S polymerase chain reaction-restriction fragment length polymorphism techniques as typing systems for thermophilic campylobacters. FEMS Microbiology Letter 211: 97-103.

Otsen, M., Bieman, M. D., Kuiper, M. T. R., Pravenec, M., Kren, V., Kurtz, T. W., Jacob, H. J., Lankhorst, E. and Zutphen, B. F. M. V. 1996. Use of AFLP markers for gene mapping and QTL detection in the rat. Genomics 37: 289-294.

Pelser, P. B., Gravendeel, B. and Meijden, R. V. D. 2003. Phylogeny reconstruction in the gap between too little and too much divergence: the closest relatives of Senecio jacobaea (Asteraceae) according to DNA sequences and AFLPs. Molecular Phylogenetics and Evolution 29: 613-628.

Riberon, A., Miaud, C., Guyetant, R. and Taberlet, P. 2004. Genetic variation in an endemic salamander, Salamandra atra, using amplified fragment length polymorphism. Molecular Phylogenetics and Evolution 31: 910-914.

Sambrook, J. and Russell, D. W. 2001. Molecular Cloning: A Laboratory Manual. Cold Spring Harbor Laboratory Press, New York.

Ude, G. N., Kenworthy, W. J., Costa, J. M., Cregan, P. B. and Alvernaz, J. 2003. Genetic diversity of soybean cultivars from China, Japan, North America, and North America ancestral lines determined by amplified fragment length polymorphism. Crop Science 43: 1858-1867.

Vos, P., Hogers, R., Bleeker, M., Reijans, M., Lee, T. V. D., Hornes, M., Frijters, A., Pot, J., Peleman, J., Kuiper, M. and Zabeau, M. 1995. AFLP: a new technique for DNA fingerprinting. Nucleic Acids Research 23: 4407-4414.

Wang, Z. Y., Tsoi, K. H. and Chu. K. H. (2003). Application of AFLP technology in genetic and phylogenetic analysis of penaeid shrimp. Biochemical Systematics and Ecology 32: 399-407. 